\title{
Büyük ve Orta Boy İşletmeler için Finansal Raporlama Standardı Açısından Maddi Duran Varlıkların Ölçüm ve Muhasebeleştirilmesi
}

Birsel Sabuncu ${ }^{1}$

\begin{abstract}
Büyük ve Orta Boy İşletmeler için Finansal Raporlama Standardı Açısından Maddi Duran Varlıkların Ölçüm ve Muhasebeleştirilmesi

Öz

Maddi duran varlıklar işletmenin temel faaliyetlerinde etkili olduğundan varlıklar içerisinde ayrı bir öneme sahiptir. Bu çalışmada maddi duran varlıkların muhasebeleştirmesi Büyük ve Orta Boy İşletmeler için Finansal Raporlama Standardı (BOBi FRS) açısından ele alınmıştır. Büyük ve Orta Boy İşletmeler için Finansal Raporlama Standardı açısından maddi duran varlıkların muhasebeleştirilmesi incelenerek Tekdüzen Muhasebe Sistemi ile benzerlikleri, farklılıkları örnek uygulamalarla ortaya konulmaktadır. Tekdüzen Hesap Planı'nda yeni hesaplara ihtiyaç vardır ve BOBI FRS' ye göre ölçüm, değerleme ile Vergi Usul Kanunu'na göre değerleme arasında farklar söz konusudur. Benzerliklerden daha çok farklılıkların olduğu anlaşılmıştır.
\end{abstract}

Anahtar Kelimeler: Maddi Duran Varlıklar, вOBi FRS, Tekdüzen Muhasebe Sistemi, Vergi Usul Kanunu
Measurement and Accounting of Tangible Fixed Assets in Terms of the Financial Reporting Standard for Large and Medium Sized Enterprises

Abstract

As tangible fixed assets are effective in the basic operations of the business, they are of a separate importance. In this study, accounting of tangible fixed assets is discussed in terms of Financial Reporting Standard for Large and Medium Sized Enterprises (FRS for LME's). In terms of the FRS for LME's, accounting of tangible fixed assets are examined and their similarities and differences with the Uniform Accounting System are demonstrated with sample applications. There are need for new accounts in the Uniform Chart of Accounts and differences between measurement, valuation according to FRS for LME's and valuation according to the Tax Procedure Law. It has been determined that the number of differences outnumber the number of similarities.

Keywords:: Tangible Fixed Assets, FRS for LMEs, Uniform Accounting System, Tax Procedure Law

\section{Giriş}

Çağımızda küreselleşme ile beraber ülkeler arasında karşılıklı ticari ilişkiler artmaya devam etmekte, ayrıca ülkeleri dışında da faaliyette bulunmak isteyen kuruluşların yakınlaşmaları, ortaklıkları, birleşmeleri söz konusu olmaktadır. Bu nedenle ülkelerin aralarında kullanabilecekleri ortak bir muhasebe dili oluşturulması ihtiyacı ortaya çıkmış ve uluslararası muhasebe standartlarının uygulanması konusunda adımların atılmasına neden olmuştur. Ülkemizde de 1994 yılından bu yana kullanılan Tekdüzen Muhasebe Sistemi'ne ilaveten Uluslararası Finansal Raporlama Standartları'nın Türkçe tercümesi olan Türkiye Finansal Raporlama Standartları (TFRS) ile Büyük ve Orta Boy İşletmeler İçin Finansal Raporlama Standardı (BOBi FRS) yürürlüğe girmiştir.

BOBं FRS, 01/01/2018 tarihi ve sonrasında başlayan hesap dönemlerinde uygulanmak üzere bağımsız denetime tabi olan firmaların 31/12/2018 tarihli finansal tablolarının hazırlanmasında uygulanacaktır. Bağımsız denetime tabi olup Türkiye Finansal Raporlama Standartları uygulamayan işletmelerin Türk Ticaret Kanunu (TTK) uyarınca finansal tablolarının gerçeğe uygun, karşılaştırılabilir finansal bilgiyi raporlama kapsamı BOBi FRS olacaktır. Literatür tara-

\footnotetext{
${ }^{1}$ Dr. Öğr. Üyesi., Pamukkale Üniversitesi Honaz Meslek Yüksekokulu, Muhasebe ve Vergi Uygulamaları. bsabuncu@pau.edu.tr, Yazar ORCID bilgisi: http://orcid.org/0000-0002-3785-5446.
} 
masında BOBi FRS ile ilgili olarak yapıımış olan belli başlı bazı çalışmalar aşağıda yer almaktadır.

Gücenme Gençoğlu (2017) “Temel Konularda BOBi FRS ve TMS/TFRS Karşılaştırılması” başlıklı çalışmasında, BOBi FRS ile TMS/TFRS temel konularda karşılaştırılarak benzer ve farklı yönleri ortaya konulmaktadır.

Ataman ve Cavlak (2017) "Büyük ve Orta Boy İşletmeler için Finansal Raporlama Standardı (BOBI FRS) ile Tam Set Türkiye Muhasebe ve Türkiye Finansal Raporlama Standartlarının (TMS/TFRS) Karşılaştırılması" başlıklı çalışmalarında, bu iki düzenleme arasındaki benzerlikler ve farklılıklar açıklanmaktadır. Değerlendirmeler sonucunda temel farklılıkların yanı sıra çoğunluk-la benzerliklerin bulunduğu tespit edilmiştir.

Doğan (2017) "Büyük ve Orta Boy İşletmeler için Finansal Raporlama Standardı ile TMS/TFRS Karşılaştırması" başlıklı çalışmasında, BOBi FRS ve TMS/TFRS hükümleri arasında benzerliklerin olduğunu vurgulanmaktadır.

Öztürk (2017) "Finansal Varlıkların Ölçme ve Muhasebeleştirme Esaslarının Büyük ve Orta Boy İşletmeler İçin Finansal Raporlama Standardı ve Türkiye Finansal Raporlama Standartları Açısından Karşılaştırılması" başııklı çalışmasında finansal varlıkların BOBi FRS ve TFRS açısından karşılaştırılmasını örneklerle açıklanmaktadır.

Şen ve Karagül (2018) “Büyük ve Orta Boy İşletmeler için Finansal Raporlama Standardına göre Ortak Kontrole Tabi İş Birleşmelerinin Raporlanmasında Kullanılacak Hakların Birleşmesi Yöntemi ve Bir Uygulama" başlıklı çalışmalarında, hakların birleşmesi yönteminin kullanılmasının uygunluğu örnek uygulama ile açıklanmaktadır.

Gökçen, Öztürk, Güleç (2018) “BOBi FRS ve TFRS'nin Finansal Raporlara Etkileri Açısından Karşılaştırılması” başlıklı çalışmalarında BOBi FRS ve TFRS arasındaki farklııklar açıklanmakta, bu farklılıkların finansal tablolar üzerindeki etkisi tartışılmaktadır.

Yelgen ve Uyar (2018) "BOBi FRS açısından Maddi Duran Varlıkların Muhasebeleştirilmesi" başlıklı çalışmalarında, maddi duran varlıklar BOBi FRS açısından ele alınmaktadır.

Güleç (2018) "Maddi ve Maddi Olmayan Duran Varlıkların BOBi FRS ve TFRS açısından Değerlendirilmesi" başlıklı çalışmasında, TFRS ve BOBi FRS açısından maddi ve maddi olmayan duran varlıkların muhasebeleştirilme farklılıkları ortaya konulmaktadır.

Bu çalışmada, Büyük ve Orta Boy İşletmeler için Finansal Raporlama Standardı́nın maddi duran varlıklar üzerindeki etkisi tartışılmaktadır. İşletmede aktifler içinde önem arz eden maddi duran varlıkların muhasebeleştirilmesi, BOBi FRS ile Tekdüzen Muhasebe Sistemi açısından karşılaştırılarak varsayımsal örnek uygulamalar ile benzerlikler ve farklılıklar ortaya konulmaktadır. BOBi FRS'ye maddi duran varlıkların muhasebeleştirilmesi için Tekdüzen Hesap Planı'nda yeni hesaplara ihtiyaç vardır. BOBi FRS'ye göre ölçüm, değerleme ile Vergi Usul Kanunu'na göre değerleme arasında farklar olduğu tespit edilmiştir.

\section{BOBI FRS'de Maddi Duran Varlıklar}

Maddi duran varlıklar faaliyetlerde bir yıldan uzun süre kullanılmak üzere edinilen, elle tutulan, gözle görülen, demode olma eskime, aşınma ile değer kaybına uğrayan, satılmak amacı taşımayan fiziki değerlerdir (Çetiner, 2009: 177).

BOBI FRS'ye göre maddi duran varlıklar ilk muhasebeleştirmede maliyet bedeli üzerinden kaydedilmektedir. Maliyet bedeli satın alma fiyatından ticari iskontolar ve indirimler çıkarıldıktan sonra, satın alma işleminden doğan giderler ve amaca uygun kullanımı için harcanan mali- 
yetlerden oluşmaktadır. Nakliye ve montaj gideri, gümrük vergileri, noter harcamaları, iade alınmayan vergi resim ve harçlar, maddi duran varlığın amaca uygun kullanımına ilişkin harcamalar, test maliyetleri, maddi duran varlığın maliyetine dahil edilebilecek giderlerdir

Tekdüzen Muhasebe Sistemi'nde maddi duran varlıklar, finansal durum tablosunun aktifinde duran varlıklar içerisinde yer almaktadır ve ilk muhasebeleştirmede maliyet bedeli üzerinden muhasebe kayıtlarına alınmaktadır. Maliyet bedeli, Vergi Usul Kanunu (VUK) madde 262'de bir iktisadi kıymetin ele geçirilmesi ya da değerini artırmak için gerçekleştirilen ödemeler ve bu kıymetle ilgili giderlerden oluşur. VUK'a göre bir iktisadi kıymetin maliyet bedeli tespit edilirken, elde etme maliyetine ek olarak bu kıymetin kullanılacak hale gelmesi için iktisadi kıymetin değerinde artış sağlayacak harcamalar da dahil edilmektedir. İktisadi varlığın alış fatura tutarı, gümrük vergisi bu varlığın işyerine getirilmesi için yapılan yükleme, boşaltma, taşıma ile sigorta-ya ait giderler, eğer vadeli alış yapıldıysa dönem sonuna kadar ortaya çıkacak finansman giderleri ve kur farkları, maliyet bedeli kapsamında değerlendirilecektir (Akdoğan, 2016: 8).

BOBI FRS'ye göre, maddi duran varlıklarda bir yıla kadar vadeli satın alımlarda vade farkı varlığın maliyet bedeline dahil edilmektedir. Fakat bir yıldan uzun vadeli maddi duran varlık satın alımında vade farkı ayrıştırılarak maddi duran varlık peşin fiyatı üzerinden varlık hesabında muhasebeleştirilmektedir. Vade farkı etkin faiz yöntemi ile hesaplanmaktadır. BOBi FRS'ye göre bir yıldan uzun vadeli alımlarında vade farkı tutarı ayrıştırılırken Tekdüzen Muhasebe Sistemi'nde vergi mevzuatı ile uyumlu olarak vade ayrıştırılmasına ilişkin bir hesap bulunmamaktadır.

BOBI FRS'de maddi duran varlıklara ilişkin borçlanma maliyetleri ortaya çıktıkları dönemde kâr veya zarara yansıtılır. Ancak inşası normal şartlar altında bir yıldan daha uzun süren maddi duran varlıkla ilgili borçlanma maliyeti kullanıma hazır hale geldiği tarihe kadar varlığın maliyetine eklenmektedir. Vergi mevzuatımızda ise, varlığa ilişkin kredinin faiz ve kur farkları maddi duran varlığın elde edildiği dönemin sonuna kadar maliyete eklenmekte ve bu dönemden sonra isteğe bağlı olarak maliyete eklenebildiği gibi gider olarak da kaydedilebilmektedir.

Sonraki ölçümde BOBi FRS'de maddi duran varlıklar için maliyet bedeli ve yeniden değerleme modeli uygulanırken vergi uygulamalarımızda sadece maliyet modeli uygulanmaktadır ve Tekdüzen Muhasebe Sistemi'ndeki hesaplar sadece bu modelin kaydına izin vermektedir.

BOBI FRS'de maddi duran varlıkların amortisman tutarlarının hesaplanarak ayrıması zorunludur ve amortismana tabi tutar maddi duran varlığın maliyet değerinden ya da yeniden değerleme sonrası kalıntı değerinin indirilmesiyle bulunmaktadır. Maddi duran varlık dönem içinde alınmış ise gün esasına göre kıst amortisman hesaplanmak zorundadır. Maddi duran varlığın amortisman tutarı varlığın faydalı ömrü boyunca dağıtılmak zorundadır. Faydalı ömür kullanım süresi olup işletme tarafından gerçekçi tahminlere dayanarak belirlenmektedir. BOBi FRS'de normal amortisman yöntemi, azalan bakiyeler yöntemi ve üretim miktarı yöntemi yer almaktadır.

VUK'da maddi duran varlığın faydalı ömrü Maliye Bakanlığı tarafından belirlenmektedir ve maddi duran varlık için binek otomobil hariç tam yıl amortisman ayrılmaktadır. Binek otomobiller için kıst amortisman uygulanmaktadır. Ayrıca, VUK hükmünce maddi duran varlıklarda amortisman beş şekilde ayrılmaktadır. Normal amortisman yöntemi, azalan bakiyeler yöntemi, fevkalade amortisman, madenlerde amortisman yöntemi ve kıst amortisman yöntemidir. 
VUK' a göre işletmede bir yıldan daha uzun süre kullanılabilen, yıpranan, eskiyen ve demode olarak değer kaybeden maddi duran varlıklar değerleme hükümlerince kanuni esaslara dayanarak belirlenecek değerlerinin amortismana tabi tutulması gerekir. Bir varlığın amortismana tabi olması bir takım şartlara bağlanmıştır. Bu şartlar; iktisadi varlığın işletme aktifinde bulunması ile bir yıldan daha uzun süre kullanılması, iktisadi varlığın aşınmaya, yıpranmaya ya da başka sebeplerle değer kaybına tabi olması, envanterde kayıtlı maddi duran varlık değerinin, her yıl yeniden belirlenmiş olan kanuni tutarlarıdır (Tuğay, 2013: 174).

\section{Maddi Duran Varlıklara iliş̧kin Muhasebe Uygulamaları}

Tekdüzen Muhasebe Sistemi'nde maddi duran varlıklar, finansal durum tablosunda aktifinde duran varlıklar içerisinde bulunmaktadır. 26 Aralık 1992 tarih ve mükerrer 21447 sayılı Resmi Gazetede Tekdüzen Muhasebe Sistemi Uygulama Genel Tebliği yayınlanmıştır. Muhasebe sistemi tebliğ hükümlerinin uygulanmaya başlaması ile işletmelerde farklı kayıt uygulamalarına son verilerek Tekdüzen Muhasebe Sistemi esasına geçilmiştir.

Aşağıda BOBi FRS açısından maddi duran varlıkların muhasebeleştirilmesindeki temel konular olan satın alınan varlıkların muhasebeleştirilmesi, vade farkları, borçlanma maliyetleri, amortisman tutarları, sonraki ölçümleri ve bilanço dışı bırakılmalarına ilişkin tasarlanmış uygulama örnekleri yer almaktadır. Söz konusu tasarlanmış uygulama örneklerine ilişkin muhasebe kayıtları kullanımdaki Tekdüzen Hesap Planı doğrultusunda ortaya konulmaktadır.

\subsection{Illk Muhasebeleştirme}

BOBI FRS'ye göre, maddi duran varlıklar ilk muhasebeleştirmede maliyet bedeli üzerinden muhasebeleştirilmektedir. Maliyet bedeline, nakliye montaj masrafları, gümrük masrafları, noter giderleri, vergi resim harçlar ve binanın yıkımına ilişkin masraflar maliyet bedeline dahil edilmektedir. Tekdüzen Muhasebe Sistemi'nde de maddi duran varlıklar ilk muhasebeleştirmede maliyet bedeli üzerinden muhasebe kayıtlarına alınır ancak borçlanma maliyetlerinin maliyet içine alınması hususunda farklııılar bulunmaktadır. BOBI FRS ve Tekdüzen Muhasebe Sistemi'nde peşin ve bir yıla kadar vadeli satın alımlarda muhasebe kayıtları aynıdır. Vadeli alımlarda ise, vergi uygulamalarımızda vade farkının ayrıştırıması gerekmez. Buna karşılık BOBi FRS'de bir yıldan kısa vadeli satın alımlarda vade farkı ayrıştırılmazken bir yıldan uzun vadeli satın alımlarda maddi duran varlık üzerinden vade farkı ayrıştırılmak zorundadır. Aşağıda bir yıldan daha uzun vadeli maddi duran varlık satın alımına ilişkin örnek uygulama yer almaktadır.

02 Ocak 2018 tarihinde KDV hariç (\%18) peşin değeri 10.000.000 TL olan bir depo 15 ay vadeli 17.500.000 TL olarak satın alınmıştır. KDV tutarı bankadan havale ile ödenmiştir.

\section{Tekdüzen Muhasebe Sistemi'ne Göre Muhasebeleştirme}

-Binanın satın alınması: 
02.01.2018

\begin{tabular}{|c|r|r|}
\hline 252 BINALAR HS. & 17.500 .000 & \\
191 INDIRILECEK KDV HS. & 3.150 .000 & \\
102 BANKALAR HS. & & \\
420 SATICILAR HS. & & \\
& & \\
\hline
\end{tabular}

Tekdüzen Muhasebe Sistemi'ne göre, maddi duran varlıkların muhasebeleştirilmesinde vade farkı tutarı ayrıştırılmadan maddi duran varlıklar grubuna kaydedilmektedir.

\section{BOBi FRS'ye Göre Muhasebeleștirme}

-Bir yıldan daha uzun vadeli satın alıma ilişkin muhasebe kaydı:

02.01.2018

252 BINALAR HS.

191 INDIRILECEK KDV HS.

3XX KISA VADELI ERTELENMIŞ FAIZ GIDERLERI HS. 4XX UZUN VADELI ERTELENMIŞ FAIZ GIDERLERI HS.

102 BANKALAR HS.

420 SATICILAR HS.

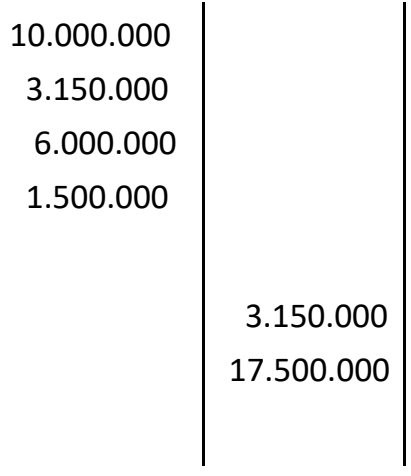

BOBI FRS'ye göre gerçekleştirilen yukarıdaki muhasebe kaydında depo bir yıldan daha uzun vadeli olarak satın alındığından peşin tutarı maddi duran varlıklar grubu içinde yer alan "252 Binalar" hesabında muhasebeleştirilirken vadeli tutar ile peşin tutar arasındaki fark ertelenmiş faiz giderleri hesabında muhasebeleştirilmektedir. Satın alım sırasında ortaya çıkan vade farkı maliyetin bir parçası olarak değil, finansman gideri olarak görülmektedir. Vade farkı ve satıcıya borç vadesi bir yıla inince de kısa vadeli hesaplara aktarılması gerekmektedir. Vadesi bir yıla düşen "Uzun Vadeli Ertelenmiş Faiz Giderleri” hesabının kalanı "Kısa Vadeli Ertelenmiş Faiz Giderleri" hesabına aktarılmakta, bu hesaptan da ilgili döneme ait kayıtlı vade farkı tutarı "780 Finansman Giderleri" hesabına aktarılarak alacak kaydedilmektedir.

-Ocak ayı vade farkı tutarının muhasebe kaydı: 
31.01.2018

780 FINANSMAN GIDERLERI HS.
3XX KISA VADELI ERTELENMiş
FAIZ GIDERLERI HS

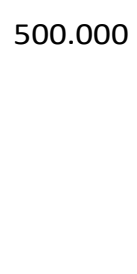

500.000

BOBI FRS ile Tekdüzen Muhasebe Sistemi arasında bir yıldan daha uzun vadeli maddi duran varlık satın alımlarında farklııı söz konusudur. BOBi FRS kapsamındaki muhasebeleştirmede vade farkının ayrıştırılarak muhasebeleştirilmesi gerekmektedir.

\subsection{Borçlanma Maliyeti}

BOBi FRS'de maddi duran varlıklarla ilgili ortaya çıkan borçlanma maliyetleri oluştukları dönemde kâr veya zarara yansıtılmaktadır. İnşaatı bir yıldan daha uzun süren maddi duran varlıklarla ilgili ortaya çıkan borçlanma maliyetleri, varlığın kullanım aşamasına kadar maliyetine eklenmektedir. Tekdüzen muhasebe Sistem'de ise, kredi faizi ve faiz ile ilgili kur farkları maddi duran varlığın edinildiği dönem sonuna kadar maliyete eklenmektedir. Daha sonra bu dönemden sonra ortaya çıkan giderler isteğe bağlı olarak maliyete eklenebildiği gibi gider olarak da kaydedilebilmektedir. Aşağıda maddi duran varlıkların inşasına ilişkin örnek yer almaktadır.

Yeni bir üretim tesisi inşaatına 01.02.2018 tarihinde başlanmıştır. Tesis inşaatında kullanmak amacıyla bankadan 01.02.2018 tarihinde ticari mevduat hesabına aktarılmak üzere faiz oranı aylık \%2'den 24 ay vadeli 5.000.000 TL tutarında kredi alınmıştır. Ayrıca inşaat ile ilgili Şubat ayı içinde KDV hariç (\%18) 5.000 TL tutarında fatura gelmiştir. Aşağıda Şubat ayına ilişkin muhasebe kayıtları yer almaktadır:

\section{BOBI FRS'ye Göre Muhasebeleștirme}

BOBI FRS'de inşası normal şartlarda bir yıldan uzun süren maddi duran varlıkların elde edilmesiyle doğrudan ilişkili olan borçlanma maliyetleri maliyete eklenmektedir. Vergi uygulamalarımızda borçlanma maliyetleri kredi faizi ile döviz kredisine ilişkin kur farkları, maddi duran varlığın elde edildiği dönemin sonuna kadar maliyete eklenmektedir. Örneğimizdeki bu tür bir faaliyette muhasebe kayıtları BOBi FRS ve Tekdüzen Muhasebe Sistemi açısından farklılık göstermemektedir.

-Tesis için alınan kredinin muhasebe kaydı:

01.02.2018

102 BANKALAR HS.

400 BANKA KREDILERI HS.

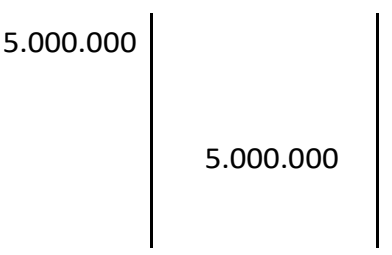

-Alınan kredinin Şubat ayına ait faiz tutarı:

$5.000 .000 \times \% 2=100.000 \mathrm{TL}$ 
28.02.2018

780 FINANSMAN GIDERLERI HS.

303 UZUN VADELI KREDILERI

100.000

ANAPARA TAKSITLERI VE FAIZLERI HS

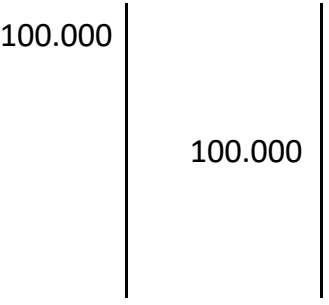

-Alınan kredinin Şubat ayına ait faiz tutarının tesis maliyetine eklenmesi:

28.02.2018

258 YAPILMAKTA OLAN YATIRIMLAR HS.

781 FINANSMAN GIDERLERI YANSITMA HS.

100.000

-Alınan kredinin Şubat ayına ait faiz tutarının yansıtma hesabı muhasebe kaydı:

28.02.2018

781FINANSMAN GIDERLERI YANSITMA HS

780 FINANSMAN GIDERLERI HS.

100.000

100.000

-Tesis inşaatı için Şubat ayı gelen faturaların muhasebe kaydı:

28.02.2018

258 YAPILMAKTA OLAN YATIRIMLAR HS.

191 INDIRILECEK KDV HS.

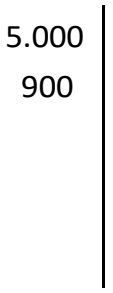

5.900

320 SATICILAR HS.

Yukarıdaki muhasebe kayıtları her ay gerçekleştirilir ve inşaat sona erdiğinde 258 Yapılmakta Olan Yatırımlar hesabının kalanı 253 Tesis Makine Cihazlar hesabına aktarılmaktadır. 2020 yılında inşaatın sona erdiğini ve 258 Yapılmakta Olan Yatırımlar hesabının kalanının 105.000 TL olduğu varsayımına ilişkin muhasebe kaydı: 
28.02.2020

253 TESIS MAKINE VE CIHAZLAR HS.

258 YAPILMAKTA OLAN YATIRIMLAR HS.

105.000

\subsection{Sonraki Ölçüm}

Maddi duran varlıkların ilk defa muhasebeleştirilmesinden sonra izleyen dönemlerde finansal tablolara yansıtılmasında esas alınacak parasal değerinin belirlenmesi işlemi olan sonraki ölçüme ilişkin olarak $\mathrm{BOB}$ I FRS'de yeniden değerleme ve maliyet modelinden biri seçebilmektedir. Vergi uygulamalarımızda sadece maliyet modeline göre ölçüm yapılmaktadır. Maliyet modeli uygulamasında BOBI FRS ve Tekdüzen Muhasebe Sistemi'ne ilişkin muhasebe kayıtları aynı olup ilk muhasebeleştirilmeden sonra maddi duran varlıklara ilişkin değer artış ve azalışları muhasebe kaydına alınmaz.

BOBi FRS'de muhasebe politikası olarak işletme tarafından yeniden değerleme modeli seçilmiş ise, maddi duran varlık ilk muhasebeleştirilmeden sonra, yeniden değerlenmiş tutarı üzerinden finansal tablolarda yer almaktadır. Maddi duran varlığın yeniden değerleme tarihindeki gerçeğe uygun değerinden birikmiş amortisman ve birikmiş değer düşüklüğü zararları düşülerek yeniden değerlenmiş tutar elde edilmektedir. Aşağıda sonraki ölçümlere ilişkin yeniden değerlemeye ilişkin örnek uygulama yer almaktadır.

01.01.2018 tarihinde depo yapmak amacıyla $\mathrm{m}^{2}$ fiyatı $2.000 \mathrm{TL} / \mathrm{m}^{2}$ olan $3.000 \mathrm{~m}^{2}$ arsa 6.000.000 TL'ye peşin olarak satın alınmıştır. 2018 yılı sonunda bölgedeki imar değişikliğinden dolayı arsa fiyatları $3.000 \mathrm{TL} / \mathrm{m}^{2}$ olmuştur.

\section{BOBi FRS'ye Göre Muhasebeleştirme}

BOBi FRS'ye göre hesaplama:

- 01.01.2018 arsa maliyeti: 6.000.000 TL

- 31.12.2018 yeniden değerlenmiş tutarı $(3.000 \times 3.000)=9.000 .000 \mathrm{TL}$

- 31.12.2018 tarihinde maddi duran varlık yeniden değerleme değerindeki artış:3.000.000TL

-Arsanın satın alınması:

01.01.2018

250 ARAZI VE ARSALAR HS.
191 INDIRILECEK KDV HS.
102 BANKALAR HS.

$\left|\begin{array}{l}6.000 .000 \\ 1.080 .000\end{array}\right|$

7.080 .000

-Yeniden değerlemeye ilişkin muhasebe kaydı: 
31.12.2018
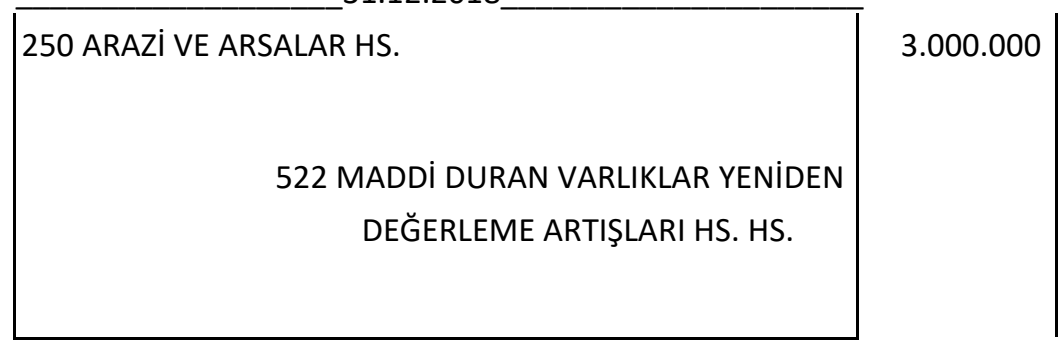

3.000 .000

Yeniden değerleme sonucunda ortaya çıkan tutar "522 Maddi Duran Varlıklar Yeniden Değerleme Artışları" hesabında muhasebeleştirilmektedir.

\subsection{Amortisman}

Amortisman, varlığın aşınma, yıpranma veya eskime payını ifade etmektedir. Maddi duran varlıklar satın alındığında aktifleştirilir. Amortisman ayırma, aşınma, yıpranma veya eskiyen maddi duran varlıkların kullanım süresince gidere dönüştürülmesidir. Kalıntı değer, varlığın tahmin edilen yararlı ömrünün sonundaki durumda elden çıkarılması sonucu elde edilmesi beklenen tutardır. Faydalı ömür ise, varlığın kullanılması beklenen süredir (Lazol, 2012: 176177).

BOBI FRS'de maddi duran varlık için amortisman ayrılması zorunlu olup amortismana tabi tutar faydalı ömrü boyunca dağıtılmaktadır. Maddi duran varlığın faydalı ömrü işletme tarafından gerçekçi tahmin ile belirlenmektedir. Amortismana tabi tutar varlığın maliyet bedelinden kalıntı değerinin indirilmesiyle ya da varlığın yeniden değerleme sonrası tutarından kalıntı değerinin indirilmesi suretiyle belirlenmektedir. Maddi duran varlık dönem içerisinde satın alınmış ise gün esasına göre kıst amortisman hesaplanmaktadır. Arsa ve araziler sınırsız faydalı ömre sahip olduklarından amortisman uygulanmamaktadır. Amortisman uygulama yöntemleri, normal amortisman yöntemi (doğrusal yöntem), azalan bakiyeler yöntemi, üretim miktarı yöntemleridir. Normal amortisman yönteminde varlığa ilişkin kalıntı değer değişmediğinde, amortisman gideri ekonomik ömür boyunca aynıdır. Azalan bakiyeler yönteminde, faydalı ömür boyunca amortisman gideri azalmaktadır. Üretim miktarı yönteminde ise, üretim miktarı üzerinden amortisman hesaplanmaktadır.

Vergi Usul Kanunu (VUK)'na göre kıst amortisman uygulaması yalnızca işletmelerin aktifinde kayıtlı binek otomobiller ile sınırlı olup binek otomobilleri dışında kalan amortismana tabi diğer varlıklar için aktife alındıkları yılda tam amortisman ayrılmaktadır. Maddi duran varlığın faydalı ömrü Maliye Bakanlığı tarafından belirlenmektedir. Aşağıda amortisman uygulamasına ilişkin örnek uygulama yer almaktadır.

Yeni bir dokuma makinesi 01.01.2017 tarihinde 5.000.000 TL tutarında banka havalesi ile ödenerek satın alınmıştır. Makinenin taşınması için 600.000 TL gider bankadan ödenmiştir. Makinenin faydalı ömrü için işletmenin gerçekçi tahmini 4 yıl olup amortisman yöntemi ise doğrusal (normal) amortisman yöntemidir. Makinenin 4. yıl sonundaki kalıntı değeri 100.000 TL olarak tahmin edilmiştir. Ayrıca, Maliye Bakanlığı'nın makinenin faydalı ömrü için belirlediği yıl ise 5 yıldır.

\section{BOBI FRS'ye Göre Muhasebeleștirme}

BOBi FRS'ye göre Normal Amortisman Yöntemi: 
- 01.01.2017 Makinenin Maliyeti: 5.000.000 TL + 600.000 TL = 5.600.000 TL

Yıllık Amortisman= (Maliyet Değeri-Kalıntı Değer) / Faydalı Ömür

- Yıllık Amortisman Tutarı (5.600.000-100.000)/4 yıl = 1.375.000 TL

-Makinenin satın alınması:

02.01.2017

253TESIS MAKINE CIHAZ HS.

191 INDIRILECEK KDV HS.

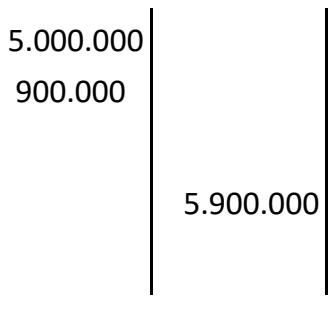

102 BANKALAR HS.

-Nakliye gideri muhasebe kaydı:

02.01.2017

253 TESIS MAKINE CIHAZ HS.

191 INDIRILECEK KDV HS.

102 BANKALAR HS

600.000

108.000

708.000

-Amortisman tutarı muhasebe kaydı:

31.12.2017

730 GENEL ÜRETIM GIDERLERI HS.

257 BIRIKMIŞ AMORTISMANLAR HS.

1.375 .000

1.375 .000

Tekdüzen Muhasebe Sistemi'ne Göre Muhasebeleștirme

Normal Amortisman Yöntemi:

- Makine Maliyeti: 5.000.000 TL + 600.000 TL = 5.600.000 TL

Yıllık Amortisman Tutarı: Maliyet Bedeli / Yararlı Ömür

- 2017 Yılı Amortisman Tutarı $=5.600 .000$ TL/5yıl $=1.120 .000 \mathrm{TL}$

-Makinenin satın alınması: 
02.01.2017

253TESIS MAKINE CIHAZ HS.

191 INDIRILECEK KDV HS.

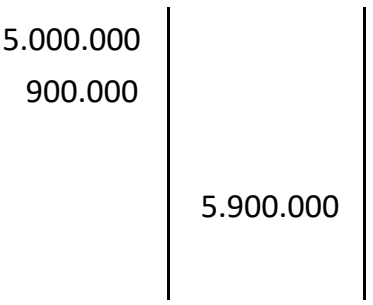

-Nakliye gideri muhasebe kaydı:

02.01.2017

253 TESIS MAKINE CIHAZ HS.

191 INDIRILECEK KDV HS.

102 BANKALAR HS.

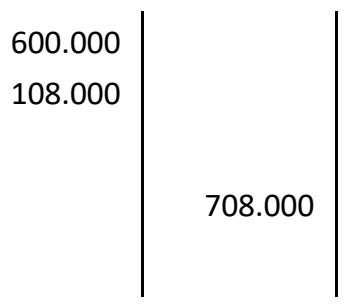

-Amortisman tutarı muhasebe kaydı:

31.12.2017

730 GENEL ÜRETIM GIDERLERI HS.

257 BIRIKMIŞ AMORTISMANLAR HS.

\subsection{Finansal Durum Tablosu Dışı Bırakma}

Bir maddi duran varlık elden çıkarıldığında veya kullanımından gelecekte ekonomik yarar beklenmediği durumlarda finansal durum tablosu dışında bırakılmaktadır. Maddi duran varlığın finansal durum tablosu dışı bırakılmasından doğan kazanç veya kayıp gelir tablosu hesaplarında Tekdüzen Muhasebe Sistemi'nde 689 Diğer Olağan Dışı Gider ve Zararlar ile 679 Diğer Olağan Dışı Gelir ve Kârlar hesabında muhasebeleştirilmektedir. BOBi FRS Kâr veya Zarar Tablosu'nda maddi duran varlıklara ilişkin satış kazanç ve zararları "Diğer Faaliyetlerden Gelirler" ve "Diğer Faaliyetlerden Giderler" hesap grubu içindedir. Bu durumda maddi duran varlığın satışı sonucunda ortaya çıkan kayıp veya kazançlar 659 Diğer Olağan Gider ve Zararlar veya 649 Diğer Olağan Gelir ve Kârlar hesabında muhasebeleştirilmektedir.

Aşağıda örnek uygulama yer almaktadır.

15.12.2018 tarihinde maliyeti 9.000.000 TL ve birikmiş amortismanı 1.200.000 TL olan makine KDV hariç (\%18) 7.000.000 TL'ye satılmıştır.

KDV tutarı: $7.000 .000 \mathrm{TL} \times \% 18=1.260 .000 \mathrm{TL}$ 


\section{Tekdüzen Muhasebe Sistemi'ne Göre Muhasebeleștirme}

15.12.2018

102 BANKALAR HS

257 BIRIKMIŞ AMORTISMANLAR HS.

689 DiĞER OLAĞAN DIŞI GIDER VE ZARARLAR HS.

253TESIS MAKINE CIHAZ HS.

9.000 .000

391 HESAPLANAN KDV HS

1.260 .000

\section{BOBI FRS'ye Göre Muhasebeleștirme}

15.12.2018

102 BANKALAR HS.

257 BIRIKMIŞ AMORTISMANLAR HS.

8.260 .000

1.200 .000

659 DiĞER OLAĞAN GIDER VE ZARARLAR HS.

800.000

253TESIS MAKINE CIHAZ HS.

9.000 .000

391 HESAPLANAN KDV HS

1.260 .000

Yukarıdaki maddi duran varlığın satışına ilişkin muhasebeleştirmede varlığın satışı sonucu zarar söz konusudur. Maddi duran varlık için önceden değer artışının muhasebeleştirildiği ve finansal tablo dışı bırakmada gelir durumunun ortaya çıktığı satışa ilişkin örnek aşağıdadır.

01.12.2018 tarihinde maliyeti 5.000.000 TL, yeniden değerleme tutarı 1.000.000 TL ve birikmiş amortismanı 2.000.000 TL olan makine KDV hariç (\%18) 8.000.000 TL'ye satılmıştır.

KDV tutarı: $8.000 .000 \mathrm{TL} \times 18=1.440 .000 \mathrm{TL}$

\section{BOBi FRS'ye Göre Muhasebeleștirme}


01.12 .2018

\begin{tabular}{|l|c|c|}
\hline 102 BANKALAR HS. & 9.440 .000 & \\
257 BIRIKMIŞ AMORTISMANLAR HS. & 2.000 .000 & \\
522 MADDI DURAN VARLIKLAR YENIDEN DEĞERLEME & 1.000 .000 & \\
ARTIŞLARI HS & & \\
253 TESIS MAKINE CIHAZ HS. & & \\
391 HESAPLANAN KDV HS & & 1.000 .000 \\
649 DiĞER OLAĞAN GELIR VE KÂRLAR HS. & & 6.000 .000 \\
& &
\end{tabular}

\section{Sonuç}

Faaliyetlerde kullanılmak üzere edinilen ve yararlanma süresi bir yıldan fazla olan fiziki varlıklar maddi duran varlıklardır. Maddi duran varlıklar satılmak amacı taşımayan, yüksek tutarlara sahip olan, gözle görülen elle tutulan değerlerdir. Maddi duran varlıkların muhasebeleştirilmesinde ülkemizde yeni yürürlüğe giren BOBi FRS ile Tekdüzen Muhasebe Sistemi uygulamalarında benzerlikler olduğu gibi farklılıklar da söz konusudur. BOBi FRS’ye göre maddi duran varlıkların muhasebeleştirilmesi için Tekdüzen Hesap Planı'nda yeni hesaplara ihtiyaç vardır ve BOBi FRS'ye göre ölçüm, değerleme ile VUK' a göre değerleme arasında farklar olduğu tespit edilmiş olup tüm bunlar aşağıda ayrıntılı olarak ele alınmaktadır:

BOBi FRS'de maddi duran varlıkların ilk defa muhasebeleştirilmesinde bir yıl veya daha kısa vadeli bir ödeme karşılığında satın alınan maddi duran varlıklarda vade farkı ayrıştırılmadan varlığın maliyet bedeli olarak muhasebeleştirilmektedir. Fakat, bir yıldan uzun vadeli bir ödeme karşılığında satın alınan maddi duran varlıklarda etkin faiz yöntemi ile vade farkı ayrıştırılarak peşin fiyatı belirlenmekte ve varlı̆̆ın maliyet bedeli peşin fiyat üzerinden muhasebe kaydına alınmaktadır. VUK' da varlığın maliyet bedeline vade farkları dahil olduğundan maddi duran varlıkların vadeli satın alımlarında vade farkı ayrıştırılmamakta ve Tekdüzen hesap Planı'nda vade ayrıştırılmasına ilişkin hesap yer almamaktadır. Vade farkı tutarı maddi duran varlığın maliyetine dahil olarak Tekdüzen Hesap Planı'nda yer alan ilgili maddi duran varlıklar hesabında muhasebe kaydına alınmaktadır. Maddi duran varlıklar ilk muhasebeleştirmede peşin ve bir yıla kadar vadeli satın alınan maddi duran varlıklarda Tekdüzen Muhasebe Sistemi ve BOBi FRS benzerlik göstermektedir.

BOBI FRS'ye göre maddi duran varlıklar için arsalar hariç amortisman ayrılması zorunludur ve kalıntı değer söz konusu olup yararlı ömür işletme tarafından belirlenmektedir. Dönem içerisinde kullanıma alınan varlıklar için kullanılan gün esasına göre kıst amortisman hesaplanmaktadır. Amortisman uygulama yöntemleri normal, azalan bakiyeler ve üretim miktarı yöntemleridir. VUK'da amortismanın faydalı ömrü Maliye Bakanlığı tarafından belirlenmektedir ve kalıntı değer dikkate alınmamaktadır. Ayrıca kıst amortisman binek otomobillere uygulanmakta ve üretim miktarı yöntemi yer almamaktadır. 
BOBI FRS'de azalan bakiyeler yönteminde amortisman oranının uygulanmasında herhangi bir sınırlama yoktur. Fakat VUK'da, azalan bakiyeler yönteminde amortisman oranı normal amortisman oranının iki katıdır ve bu oran hiçbir zaman \%50'yi aşamaz.

BOBi FRS'de maddi duran varlığın ilk muhasebeleştirmeden sonraki ölçüm maliyet veya yeniden değerlenen değer üzerinden gerçekleştirilmektedir. Varlığın değerleme tarihindeki gerçeğe uygun değer tutarının kim tarafından belirlendiği dipnotlarda açıklanmaktadır. Değerleme değerindeki artış özkaynaklarda yeniden değerleme yedeği olarak kaydedilmektedir. VUK'da sadece maliyet modeli uygulanmaktadır ve Tekdüzen Hesap Planı'ndaki hesaplar sadece bu modelin kaydına izin vermektedir.

BOBI FRS'de maddi duran varlıklarla ilgili borçlanma maliyetleri gerçekleştikleri dönemde kâr zararda muhasebeleştirilmektedir. İnşası bir yıldan daha uzun süren varlıklarda borçlanma maliyetleri kullanıma kadar maliyete dahil edilmektedir. Tekdüzen Muhasebe Sistemi'nde maddi duran varlıkla ilgili kredi faizi ve kur farkları dönem sonuna kadar maliyette daha sonra maliyet veya gider hesaplarında muhasebeleştirilebilmektedir.

BOBi FRS'de maddi duran varlığın finansal tablo dışı kalması durumda ortaya çıkan kazanç veya kayıplar "Diğer Faaliyetlerden Gelirler" ve "Diğer Faaliyetlerden Giderler" hesap grubu içerisinde yer almaktadır. Tekdüzen Muhasebe Sistemi'nde ise, maddi duran varlıkların satışına ilişkin ortaya çıkan kazanç veya kayıplar "Olağan Dışı Gider ve Zararlar" ile Olağandışı Gelir ve Kârlar" hesap grubu içinde yer almaktadır.

Bundan sonraki çalışmalarda maddi duran varlıklar gibi işletmede önem arz eden varlık ve yükümlülüklere ilişkin ölçüm ve muhasebe esaslarının BOBi FRS ve yürürlükteki uygulamalar ile benzerlik ve farklılık açısından ele alınması hem literatüre katkı sağlayacak hem de uygulamada yol gösterici olacaktır. 
Aralık 2019, C. 14, S. 3

\section{Kaynaklar}

Akdoğan, Nalan (2016), VUK Yasası'nın Muhasebe Standartları ile Uyumlu Hale Gelmesi İçin Yapılması Gereken Değişikliğe ilişkin Öneriler, Gazi Kitabevi, Ankara.

Ataman, Başak; Cavlak, Hakan (2017), "Büyük ve Orta Boy İşletmeler İçin Finansal Raporlama Standardı (BOBi FRS) ile Tam Set Türkiye Muhasebe ve Türkiye Finansal Raporlama Standartlarının (TMS/TFRS) Karşılaştırılması”, Finans Ekonomi ve Sosyal Araştırmalar Dergisi, Cilt:2, Sayı:3, 153-167.

Çetiner, Ertuğrul (2009), Genel Muhasebe, 2. Baskı, Gazi Kitabevi, Ankara.

Doğan, Aziz (2017), "Büyük ve Orta Boy İşletmeler için Finansal Raporlama Standardı ile TMS/TFRS Karşılaştırması", işletme Araştırmaları Dergisi, Cilt:9 (4), 770-786.

Gençoğlu, Gücenme, Ümit (2017), "Temel Konularda BOBi FRS ve TMS/TFRS Karşılaştırması”, Muhasebe Finansman Dergisi, Sayı: 76, 1-24.

Gökçen, Gürbüz; Öztürk, Erkan; Güleç, Faruk, Ömer (2018), “BOBi FRS ve TFRS’ nin Finansal Raporlara Etkileri Açısından Karşılaştırılması" Finans Ekonomi ve Sosyal Araştırmalar Dergisi, Cilt: 3, Sayı:2, 437-457.

Güleç, Faruk, Ömer (2018), "Maddi ve Maddi Olmayan Duran Varlıkların BOBi FRS ve TFRS Açısından Değerlendirilmesi", Işletme Araştırmaları Dergisi, Cilt: 10 (4), 901-921.

Kamu Gözetimi, Muhasebe ve Denetim Standartları Kurumu (2017), Büyük ve Orta Boy İşletmeler İçin Finansal Raporlama Standardı, http://www.resmigazete.gov.tr, (Erişim:26.01.2018).

Lazol, Ibrahim (2012), Genel Muhasebe, Ekin Kitabevi, 18. Baskı, Bursa.

Öztürk, Can (2017), “Finansal Varlıkların Ölçme ve Muhasebeleştirme Esaslarının Büyük ve Orta Boy İşletmeler İçin Finansal Raporlama Standardı ve Türkiye Finansal Raporlama Standartları Açısından Karşılaştırılması", İ̧letme Araştırmaları Dergisi, Cilt:9 (3), 594-617.

Şen, Kıymetli, Illker; Karagül, Arman, Aziz (2018), “Büyük Ve Orta Boy İşletmeler İçin Finansal Raporlama Standardına Göre Ortak Kontrole Tabi İş Birleşmelerinin Raporlanmasında Kullanılacak Hakların Birleşmesi Yöntemi Ve Bir Uygulama”, Muhasebe ve Vergi Uygulamaları Dergisi, Özel Sayı, 169- 187.

Tuğay, Osman (2013), "Maddi Duran Varlıklarda Amortisman Uygulamalarının TMS 16 ve Vergi Mevzuatı Açısından incelenmesi", Çukurova Üniversitesi, iktisadi Idari Bilimler Fakültesi Dergisi, Cilt.17, Sayı.2, 167-187.

Yelgen, Esin; Uyar, Süleyman (2018), "BOBi FRS Açısından Maddi Duran Varlıkların Muhasebeleştirilmesi”, Muhasebe ve Vergi Uygulamaları Dergisi, Özel Sayı, 98-109. 
Eskişehir Osmangazi Üniversitesi iiBF Dergisi 